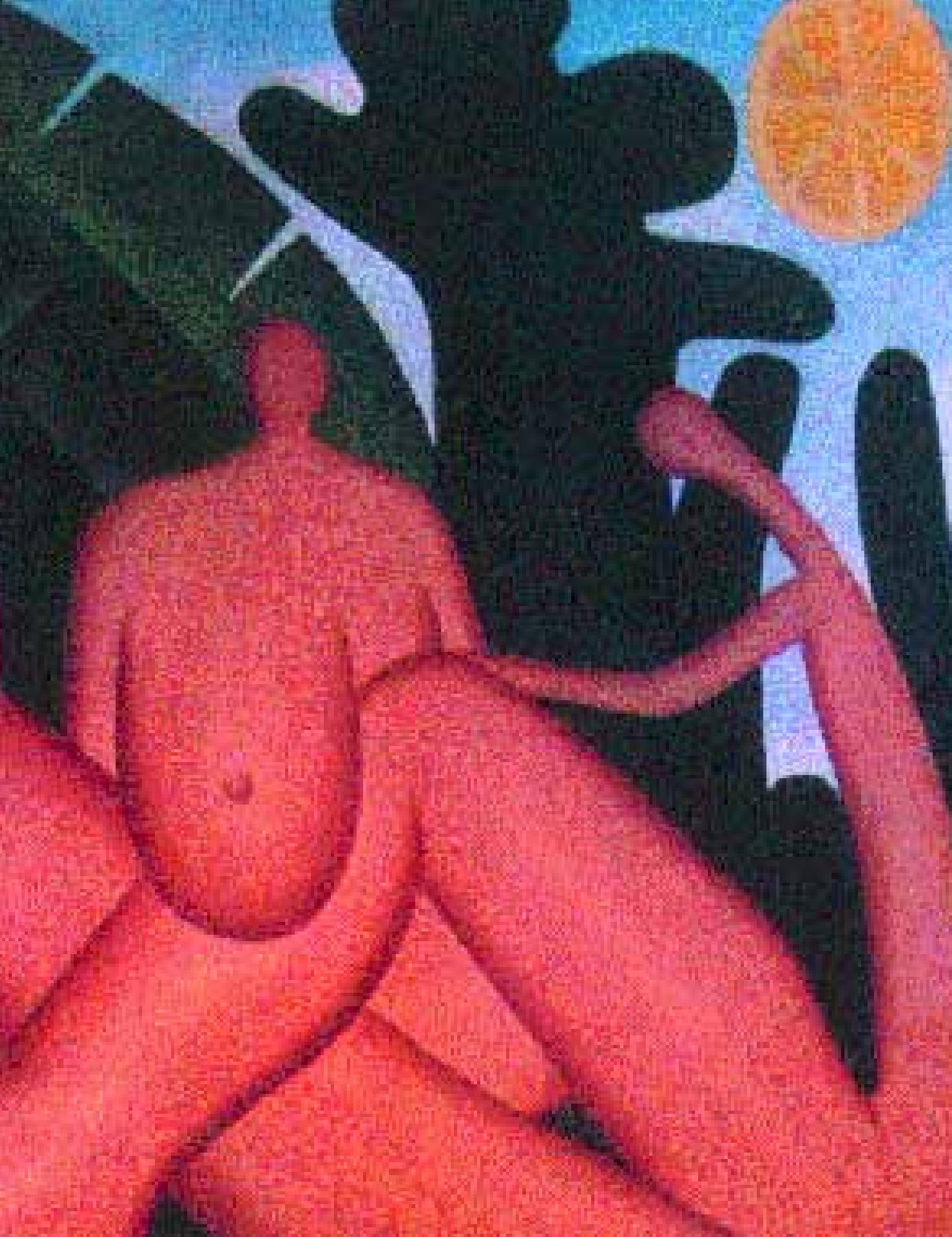

ch- 


\section{Indigestão antropofágica}

1 importação e o uso indiscriminado de tecnologia gerencial vinda de países desenvolvidos podem provocar efeitos colaterais indesejáveis, como a perda da visão estratégica ou a incontinência verbal. A solução é retomar os antigos rituais antropofágicos e mandar para o caldeirão as dezenas de gurus e curandeiros que invadiram a Terra Brasilis. Os que provarem seu valor poderão ser adotados.

por Miguel P. Caldas e Thomaz Wood Jr. FGV-EAESP

À época do descobrimento, o Brasil era habitado por cerca de 1 milhão de índios, aproximadamente a mesma população do país dos descobridores. Os nativos foram, em sua maioria, dóceis e servis ao colonizador.

Porém, entre esses povos havia tribos que praticavam a antropofagia, um ritual de guerra no qual os vencedores alimentavam-se, literalmente, dos vencidos. Ao devorar o vencido, o vencedor acreditava estar sugando sua coragem e energia, em um ato de respeito e honra. Portanto, era preciso que o vencido fosse um guerreiro corajoso, à altura de seu contendor.

Como se sabe, a antropofagia foi retomada, como metáfora, no início do século XX, pela vanguarda cultural paulistana. Essa vanguarda denunciava o que entendia ser uma apropriação exagerada e sem sentido da cultura estrangeira. Ao mesmo tempo, os intelectuais que a forma- 
vam estavam comprometidos com a modernidade e o cosmopolitismo de sua época. Propunham a apropriação sem pudores de idéias e conceitos estrangeiros, porém defendiam que fossem temperados por novos significados e alterados por cores e valores locais.
À medida que o Brasil, como outros países emergentes, insere-se em uma nova ordem econômica, crescem pressões para a adoção de práticas gerenciais mais avançadas, que capacitem as empresas locais a competir em um cenário globalizado. Entretanto, parece claro que a pura e simples adoção de modelos alienígenas pode ser frustrante e desastrosa. Por isso, sugerimos que chegou novamente o momento para retomar o antigo ritual antropofágico e levar para o caldeirão as dezenas de Druckers, Porters, Senges, Hammers e Prahalads que inundam o discurso e a prática de consultores e executivos. Os que provarem sua coragem, valor e adequação ao contexto poderão ser adotados.

Importar é o que importa.

No início do século XXI, vemo-nos diante de contexto similar ao que alimentou a crítica e a criatividade do movimento modernista de Oswald de Andrade. Encontramo-nos, uma vez mais, diante da apropriação exagerada e sem sentido de artefatos estrangeiros. Referimo-nos aqui, especificamente, à importação e adoção de tecnologia gerencial originária dos países desenvolvidos, embora a questão seja pertinente a todos os demais domínios da vida social e econômica.
Como alguns outros países emergentes, após décadas de isolamento e políticas protecionistas, só recentemente o Brasil acordou para o mundo exterior. Problemas de base no campo econômico e social levam à persistência do subdesenvolvimento. Por outro lado, pressões econômicas reais, provocadas pela inserção do país no mercado internacional, causam uma corrida frenética para recuperar o tempo perdido.

\section{Quadro: $O$ ambiente empresarial brasileiro}

\section{INSTITUIÇÕES}

- baixo grau de institucionalização dos organismos de controle e coordenação.

- baixa intensidade de competição, com a presença de monopólios e oligopólios.

- regulamentação precária da atividade empresarial: excesso de regulamentação em alguns casos, falta de regulamentação em outros.

- comunicação imperfeita no mercado.

- relações conflituosas entre clientes e fornecedores, dificultando alianças e parcerias.

\section{CULTURA}

- personalismo: 0 indivíduo acima da comunidade.

- ambigüidade: nada é o que parece ser, e, quando é, pode também ser algo mais.

- alta distância do poder: relações sociais marcadas pela herança escravocrata.

- plasticidade e permeabilidade: abertura e fascinação com 0 estrangeiro.

- formalismo e "faz de conta": convivência entre o"mundo de direito" e o "mundo de fato", mediada pela ambigüidade e pelos comportamentos de fachada.

\section{ORGANIZAÇÕES}

- estratégia pouco focada em função de pequena tradição no tratamento da questão e das condições ambientais instáveis.

- estrutura: presença ainda importante de estruturas hierárquicas pesadas e de formas primitivas de organização do trabalho.

- estilo gerencial marcado pelo autoritarismo, forte hierarquização das relações de poder e centralização das decisões.

- sistemas de informação ainda incipientes, com retenção da informação no topo.

- sistemas de apoio pouco desenvolvidos. 
O empresariado local, acostumado a condições de concorrência controlada e operando em um mercado protegido, viu-se despreparado para a concorrência internacional. Enquanto as pressões econômicas determinam "o que dever ser feito" - modernização da gestão, aumento da produtividade, redução de custos etc. -, o discurso "gerencialista" dominante, permeado pela idéia de validade universal dos conceitos administrativos, aponta o "como deve ser feito". Ou seja, a competitividade deve ser atingida pela difusão de "modelos de excelência". Tais modelos, presumidamente, poderiam ser transplantados dos países desenvolvidos para as nações emergentes.

Os traços culturais brasileiros servem de pano de fundo para a ação dos agentes de difusão de tecnologia administrativa estrangeira: o Estado, as escolas de administração, as empresas de consultoria e algumas entidades profissionais. Assim, as empresas importam, em grande quantidade e com pouco critério, modelos de gestão, modas e gurus tidos como modernos. Forma-se com isso um mercado para compra, embalagem e venda de tecnologia gerencial importada.

Seria possível argumentar que o desenvolvimento das economias emergentes levaria à adoção de instituições e políticas industriais similares às dos países desenvolvidos. E que, portanto, não haveria problema algum com a importação. Isso pode de fato ocorrer. Porém, esse argumento contém pelo menos duas imperfeições: primeiro, não é possível saber exatamente em que velocidade tais instituições irão amadurecer; e, segundo, nada garante que esse amadurecimento irá levar à mesma configuração dos países desenvolvidos. Portanto, é fundamental considerar as peculiaridades do ambiente empresarial brasileiro e suas características institucionais, culturais e organizacionais (ver quadro).

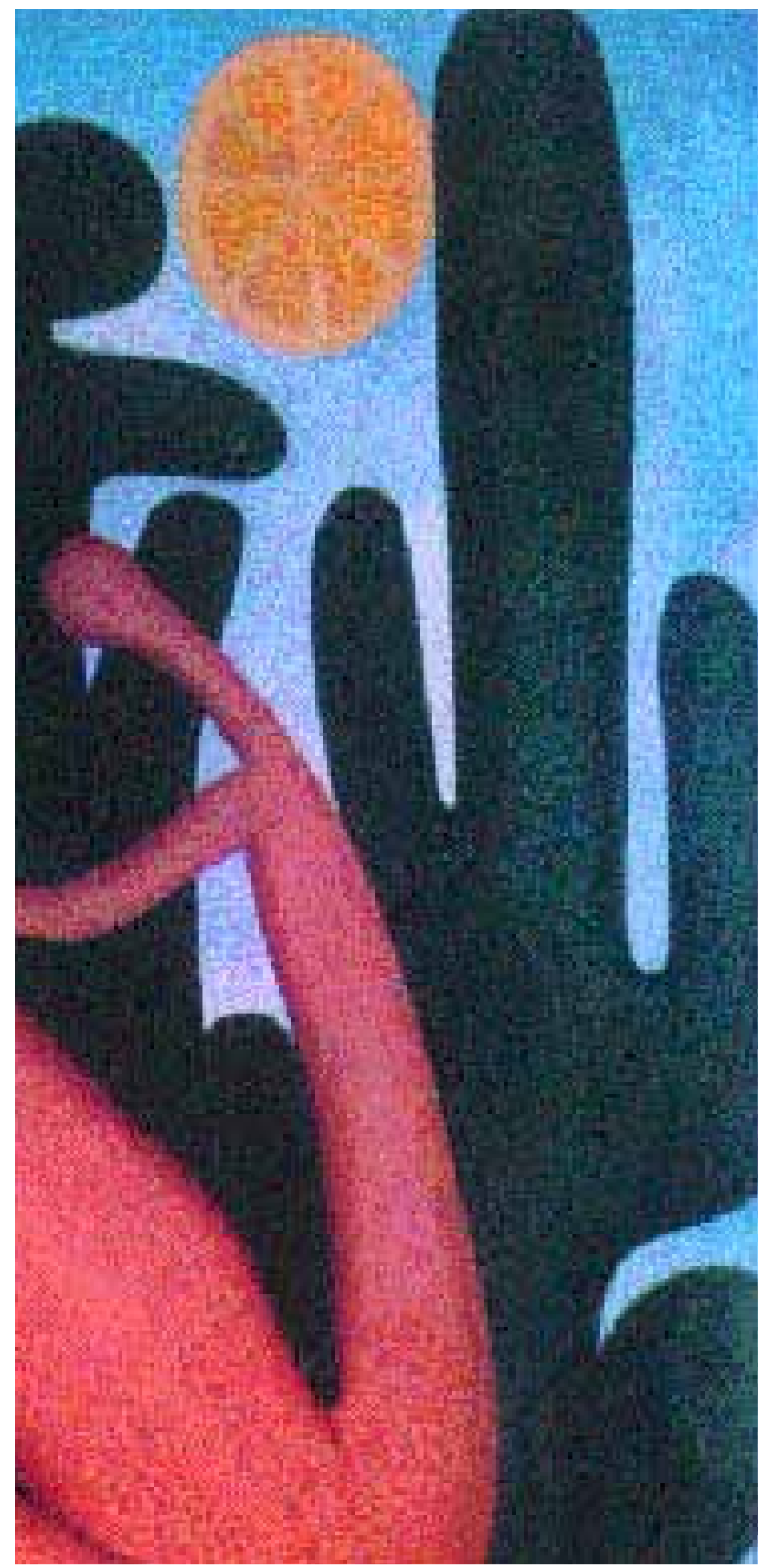


Duas indigestões e um final feliz. Mas como reagem as empresas à importação e ao uso de tecnologia empresarial importada? Pesquisas conduzidas pelos autores em empresas locais passando por processos de mudança sugerem que a importação de tecnologia gerencial em contextos particulares, como o brasileiro, pode gerar consequêencias que contrariam as expectativas dos adotantes.

\section{Ao adotar modelos importados}

segundo o conceito de antropofagia

organizacional, as empresas procuram

extrair o melhor deles, traduzindo-os

para seu universo sócio-cultural.

Identificamos três reações que podem ser consideradas típicas: (1) comportamento "para inglês ver"; (2) frustração e negação; e (3) adaptação criativa. Também observamos que os três comportamentos podem conviver em uma mesma organização, ou em um mesmo processo, mas um deles tende a predominar sobre os demais.

Mudança "para inglês ver". Este parece ser o mais típico comportamento organizacional brasileiro frente à importação de conceitos. Consiste em adotar de forma temporária e/ou parcial a tecnologia em questão para aplacar as pressões de adoção, sem, no entanto, realizar mudanças substanciais ou ferir aquilo que se considera intocável em termos de status quo. Quando tal reação ocorre, o olhar estrangeiro percebe apenas uma pseudo-realidade, que parece conformar-se aos modelos e referenciais importados. Porém, isso constitui apenas aparência. Abaixo da superfície - plástica e permeável ao novo - permanece uma substância híbrida e ambígua, apenas parcialmente receptiva a modelos alienígenas. Erroneamente, tem-se a sensação de que a realidade organizacional brasileira esteja povoada por fenômenos gerenciais típicos, idênticos a padrões internacionais, quando de fato existe uma realidade distinta, disfarçada "para inglês ver".
Frustração e negação. Uma segunda reação ocorre quando a adoção da tecnologia estrangeira não tem como funcionar e sua dissimulação "para inglês ver" é inviável. É o caso de organizações protegidas por regulamentação governamental, ou que se encontram em segmentos ainda dominados por oligopólios. Quando expostas à perspectiva de mudanças radicais no cenário competitivo, essas organizações costumam procurar socorro em grandes empresas de consultoria. Sua expectativa é de que amplos processos de mudança possam redimi-las de sua condição anacrônica. Implicitamente, entretanto, predomina a vontade de que tudo mude para que fique exatamente como está e que o status quo não seja alterado. Na prática, as mudanças propostas costumam esbarrar em estruturas de poder e condições operacionais não previstas nos pacotes. O resultado é a frustração diante da impossibilidade de realizar a transformação desejada sem dor ou a simples negação da metodologia como não apropriada ao contexto.

Adaptação criativa. Por fim, uma terceira reação é aquela em que a organização não procura fingir que adota uma técnica estrangeira na qual não acredita, mas tampouco a nega. Nesse caso, o que ocorre é uma adaptação dos conceitos à realidade local para atender aos objetivos singulares da organização. A adaptação criativa remete ao conceito de antropofagia organizacional. Ao adotar modelos importados segundo tal conceito, organizações procuram extrair o melhor deles, traduzindo a tecnologia para seu universo sócio-cultural e fazendo uma apropriação sem preconceitos. Esse processo exige conhecimento profundo das variáveis institucionais, culturais e organizacionais.

O fenômeno aqui analisado não é exclusivo do ambiente brasileiro: seja a tendência à importação, ou as reações causadas pela incompatibilidade com peculiaridades locais, ou ainda a capacidade de adaptação antropofágica. Os conceitos sugeridos podem ser adequados à realidade de outros países emergentes - em função de similaridades sociais, econômicas e culturais - tanto como à realidade de alguns países desenvolvidos. As condições do Brasil podem ampliar ou dar tempero particular aos fenômenos e reações estudados, mas eles não lhe são, de forma alguma, exclusivos. 


\section{Banquete arriscado}

maginemos que a sugestão dos autores inesperadamente se materializasse, que os velhos hábitos voltassem e que a deglutição de carne humana se tomasse novamente rotina. Então...

Fim de tarde em um conhecido hospital de São Paulo. 0 diretor de marketing de uma multinacional européia convalesce de uma forte indigestão. Um colega entra no quarto para uma rápida visita.

- Puxa! Você nos pregou um susto.

- Pois é, eu mesmo achei que não ia escapar com vida.

- Mas os médicos já descobriram o que foi? Talvez um Gary Hamel estragado...

- Não, não. Achei que tinha sido um Stephen Covey "a la mode" que eu comi na segunda-feira. Mas o patologista disse que pode ter sido o Porter do mês passado. É assim mesmo. No princípio você acha que ganhou visão estratégica. Começa a tomar decisões importantes e fazer mudanças no portfolio de negócios. Um mês depois começam as alucinações: cadeias de valores, matrizes de competitividade e análises SWOT. Então, cada vez que você tem que tomar decisões práticas, vêm as náuseas e dores de cabeça. Mas 0 médico disse que vou superar.

- A coisa está feia! Ontem ouvi falar de um sujeito internado por causa de um laccoca mal passado. Começou a ter delírios de grandeza. Um médico disse que estão pensando em abrir uma clínica só para vítimas de Welchs, Gates e laccocas. Parece que ainda não conseguiram achar um tratamento eficaz. Ataca diretamente 0 cérebro. 0 sujeito perde 0 senso de ridículo. 0 pior é que vicia e 0 cara não consegue mais viver sem a coisa. É pior que droga.

- É mesmo? No meu caso parece que os efeitos são temporários. Perdi a visão estratégica, mas com terapia posso recuperar até $50 \%$.

-Tenho certeza que você vai superar. Parece que Porter não é fatal. Se tivesse sido Senge ou Deming poderia ser pior.Você lembra do diretor da filial do Rio de janeiro? Comeu um Senge e começou a delirar. Só fala em pensamento sistêmico e aprendizado organizacional. Corre o boato que vai ser aposentado por invalidez.

Não muito longe do hospital, um repórter investigativo entra em cena e revela a crueza dos fatos:

Aos 500 anos da invasão do Brasil por Portugal, finalmente a coisa pegou. 0 primeiro sinal veio em 13 de maio de 1997, data na qual o príncipe dos gurus, Michael Porter, brindou-nos com sua sabedoria. Falando para um seleto grupo de líderes tupiniquins, ele catequizou e motivou. Foi visto pela última vez dando autógrafos para uma fila de (aparentemente) bem comportados executivos.
A verdade só veio à tona meses depois. Um empresário, dando entrevista para uma revista de negócios, deu com a língua nos dentes ao ser perguntado sobre 0 segredo de sua nova estratégia: 0 príncipe dos gurus havia tido o mesmo destino que o saboroso bispo Sardinha mais de 400 anos antes, deglutido pelos povos locais.

Por mais estranho que possa parecer, e ao contrário do esperado, a declaração não causou comoção. Afinal, finalmente retomávamos nossas raízes e realizávamos o chamado "ideal antropofágico".

Também não assustamos os vizinhos do Norte. "Coisa de brasileiro", devem ter pensado os gringos. E olhando pelo lado comercial, 0 acordo era mais do que justo. Havíamos pagado regiamente por um guru já bem usado. Além do mais, a indústria de curandeiros do Massachusetts não parava de produzir e os próprios norteamericanos já não sabiam 0 que fazer com tantos clones. Um a mais, um a menos não faria a menor diferença.

Entre as empresas que implantaram mudanças radicais em 1997 (a maioria desastrosa, convém notar), nada menos que 12 tiveram diretores envolvidos no episódio de 13 de maio. Por isso a deglutição de Porter ficou conhecida como o "banquete dos doze".

A notícia correu e logo a procura por carne de qualidade deixou de ser assunto de bastidores para ocupar salas de aula, escritórios de consultoria e redações de revistas de negócios.

Porém, sem dúvida alguma, o marco da retomada antropofágica foi a inauguração, em um elegante bairro paulistano, do HSM Grill. Rodeado por bem cuidadas árvores de pau-brasil, a elegante mansão fora transformada em requintado restaurante. 0 mâitre e as garçonetes, vestidas em legítimos "Jim-das-Selvas", recebem os freqüentadores, tratando-os sempre pelo brasileiríssimo "sim, Saib!"

0 cardápio faz justiça ao requintado ambiente. 0 forte, naturalmente, são as cames norte-americanas. A alcatra Porter, praticamente desaparecida, é vendida em tirinhas de 50 gramas. 0 filé Kotler ainda pode ser encontrado em porções maiores, mas circulam rumores que um importante fabricante de alimentos, precisando renovar sua combalida estratégia de produtos, teria reservado dois quilos do estoque para um banquete com a diretoria.

Não faltam alternativas: para empresas precisando melhorar competências, 0 indicado é a picanha Prahalad. Se o caso é de reestruturação e dificuldades com a visão de futuro, o mais adequado é um Hammer ao molho Naisbitt. Se as coisas não vão mal e basta manter o otimismo, então uma sopinha Drucker pode cair muito bem. A coisa toda funcionaria muito bem não fossem os abusos e efeitos colaterais, como os que vitimaram o diretor de marketing. 